\title{
The exception to the rule: retreating ice front makes Bewick's swans Cygnus columbianus bewickii migrate slower in spring than in autumn
}

\author{
Rascha J. M. Nuijten, Andrea Kölzsch, Jan A. van Gils, Bethany J. Hoye, Kees Oosterbeek, \\ Peter P. de Vries, Marcel Klaassen and Bart A. Nolet
}

R. J. M. Nuijten, A. Kölzsch, J. A. van Gils, B. J. Hoye, M. Klaassen, P. P. de Vries and B. A. Nolet (b.nolet@nioo.knaw.nl), Dept of Animal Ecology, Netherlands Inst. of Ecology (NIOO-KNAW), PO Box 50, NL-6700 AB Wageningen, the Netherlands. RJMN, AK, PPV and BAN also at: Project group Movement Ecology, NIOO-KNAW. RJMN also at. Utrecht Univ., Dept Biology - Environmental Biology, PO Box 80125, NL-3508 TC Utrecht, the Netherlands. Present address of JAvG: Dept of Marine Ecology, Royal Netherlands Inst. for Sea Research (NIOZ), PO Box 59, NL-1790 AB Den Burg (Texel), the Netherlands. Present address of BJH: Dept of Ecology and Evolutionary Biology, Univ. of Colorado, Ramaley N122, Campus Box 334, Boulder, CO 80309-0334, USA. Present address of MK: Centre for Integrative Ecology, Deakin Univ., Geelong, VIC 3220, Australia. - K. Oosterbeek, Dutch Centre for Field Ornithology (Sovon), PO Box 6521, NL-6503 GA Nijmegen, the Netherlands.

\begin{abstract}
In the vast majority of migratory bird species studied so far, spring migration has been found to proceed faster than autumn migration. In spring, selection pressures for rapid migration are purportedly higher, and migratory conditions such as food supply, daylength, and/or wind support may be better than in autumn. In swans, however, spring migration appears to be slower than autumn migration. Based on a comparison of tundra swan Cygnus columbianus tracking data with long-term temperature data from wheather stations, it has previously been suggested that this was due to a capital breeding strategy (gathering resources for breeding during spring migration) and/or to ice cover constraining spring but not autumn migration. Here we directly test the hypothesis that Bewick's swans Cygnus columbianus bewickii follow the ice front in spring, but not in autumn, by comparing three years of GPS tracking data from individual swans with concurrent ice cover data at five important migratory stop-over sites. In general, ice constrained the swans in the middle part of spring migration, but not in the first (no ice cover was present in the first part) nor in the last part. In autumn, the swans migrated far ahead of ice formation, possibly in order to prevent being trapped by an early onset of winter. We conclude that spring migration in swans is slower than autumn migration because spring migration speed is constrained by ice cover. This restriction to spring migration speed may be more common in northerly migrating birds that rely on freshwater resources.
\end{abstract}

In the majority of migrating bird species studied so far, spring migration proceeds faster than autumn migration (Fransson 1995, Alerstam et al. 2006, Yohannes et al. 2009, Karlsson et al. 2011, Klaassen et al. 2012, La Sorte et al. 2013, Nilsson et al. 2013). There are both proximate and ultimate explanations for this phenomenon. A proximate explanation is that migratory conditions are better in spring, with higher food availability (Van der Graaf et al. 2006), longer days (Bauchinger and Klaassen 2005) and/or more wind assistance (Kemp et al. 2010). An ultimate explanation is that there is intense competition for breeding territories, selecting for rapid migration in spring in order to arrive early at the breeding grounds (Kokko 1999, Smith and Moore 2005, Nilsson et al. 2013).

Depending on the distance, flight mode, flight speed and (re)fuelling rates, migration may constitute a substantial part of a bird's annual cycle (Berthold 1996, Newton 2008). This annual cycle is often very tightly scheduled, especially in larger birds, as they generally require more time than smaller birds to complete their breeding cycle (egg laying, incubation and chick rearing) and moult (Rohwer et al. 2009). In addition, larger birds can store less fat reserves, relative to body mass, which limits their maximum flight range without refuelling (Alerstam et al. 2003), and may also have proportionally lower refuelling rates than smaller birds (Lindström 2003). As a result, migration speed is expected to be slower in large birds than in small birds, particularly in birds using flapping flight (Hedenström and Alerstam 1998). Migration speeds derived from empirical relationships do not yield strong effects of body mass (Klaassen 2003; but see La Sorte et al. 2013), but the effect is evident when the need for bringing stores to the breeding grounds ('capital breeding', Drent and Daan 1980) is taken into account (Nolet 2006). These aspects collectively increase selection pressures on 
migration speed and timing in larger birds (Hedenström and Alerstam 1995, Alerstam 2011).

Bewick's swans Cygnus columbianus bewickii are among the largest long-distance migratory birds using flapping flight (Hedenström and Alerstam 1998), and are therefore an interesting study species with regard to the tight annual cycle and corresponding selection pressures on migration speed and timing. During migration, these swans stop several times to refuel and, in spring, accumulate body reserves for breeding (Beekman et al. 2002, Nolet 2006). They are dependent on open, shallow water to feed on aquatic vegetation (Beekman et al. 1991, Nolet and Drent 1998, Nolet et al. 2001, Hoye et al. 2012), on which they can attain high daily intakes (Klaassen et al. 2010).

Counter to the majority of avian migration schedules, swan migration appears to proceed faster in autumn than in spring. This was first observed by Evans (1982) and later substantiated by observations of Luigujōe et al. (1996), both based on resightings of marked birds. Beekman et al. (2002) and Petrie and Wilcox (2003) confirmed this pattern by satellite tracking Bewick's swans and tundra swans Cygnus columbianus columbianus, respectively. Petrie and Wilcox (2003) also proposed two hypotheses to explain this seasonal difference. The first states that the birds move slower during spring migration because they have to build up additional stores during migration and carry these to the breeding grounds in order to be able to commence breeding upon arrival ('capital breeding') (Petrie and Wilcox 2003). The second hypothesis states that the birds might be constrained by ice cover in spring and must wait for the ice to melt to be able to access aquatic vegetation, whereas in autumn they fly ahead of the ice and are even being driven south by advancing winter conditions, thus migrating faster (Petrie and Wilcox 2003). Nolet (2006) tested these two hypotheses for all four populations of tundra swans Cygnus columbianus (Bewick's swans being a subspecies), by comparing the movements of satellite-tracked swans (1990-2000) with longterm mean-monthly temperature data (1961-1990) from weather stations along the migratory routes. Temperatures above freezing were used as an indicator of retreating ice (Mathiasson 1991). The findings show that spring migration speed of swans is in accordance with capital breeding, but that the degree of capital breeding varies among populations, depending on the flight distance between the final stop-over site and the breeding grounds and the pace of spring advancement. The first hypothesis thus does not hold true for all populations, nor for the whole of spring migration. Additionally, spring migration speed did seem to be constrained by the onset of spring, which is in accordance with the second hypothesis (Nolet 2006). However, the temperature data that were used in Nolet (2006) were not collected over the same years as the swan movements, and ice cover was not measured directly.

In this study, we aimed to test the second hypothesis directly by comparing the migratory movements of individual swans (using GPS-tracking) with concurrent real-time ice cover data, collected by satellite imagery, at important migratory stop-over sites across multiple years (2007-2011). We studied the migration of the western population of Bewick's swans wintering in western Europe (mainly in the British Isles, the Netherlands and Germany) and breeding on the tundra in European Russia (Rees et al. 1997). We predict that in spring the speed of swan migration corresponds to that of the retreating ice as the swans will closely follow the ice front, whereas in autumn we expect the swans to move ahead of the upcoming ice into ice-free areas.

\section{Methods}

\section{Testing of GPS collars}

We used neck collars with an in-built GPS data logger (total weight $75 \mathrm{~g}$ ). First, we tested the quality of the fixes by setting out four GPS loggers (eight fixes a day) at a fixed position $10 \mathrm{~m}$ apart. The precision (i.e. mean deviation from the mean of 94 fixes) was on average $3.5 \mathrm{~m}$. Comparison with the coordinates of the fixed positions measured with a differential GPS (DGPS) receiver yielded an accuracy (i.e. mean deviation from the DGPS position) of $3.6 \mathrm{~m}$ on average.

Second, we examined the effect of the GPS collars on swan behaviour using captive Bewick's swans. Eight adult Bewick's swans were grouped in pairs, and each pair was housed in an outdoor compartment $(10 \times 5 \mathrm{~m}$ each $)$ with empty compartments in between. In period 1 (eight weeks in June-July), one member of each pair was equipped with a GPS collar, and the other member served as a control; in period 2 (8 weeks in September-October) the roles were reversed. On four days a week (Tuesday, Wednesday, Thursday and Friday), starting at four different times (09:00, $11: 00,13: 00$ or 15:00), a pair was observed for $1 \mathrm{~h}$ in a Latin-square design (i.e. $4 \mathrm{~h}$ of observation per pair per week); one Latin-square covered four weeks, and was repeated in the next four weeks. During the observations the time spent preening (including pecking at the collar in case of the collared bird) was recorded to measure the time needed to become accustomed to the GPS collars. The birds were weighed once a week and their weight change (dW, expressed in $\mathrm{g} \mathrm{d}^{-1}$ ) was used to compare between the collared and noncollared birds.

\section{GPS tracking of swan migration}

During winter a total of 108 Bewick's swans were caught by canon netting in the Netherlands (2006/2007: 28, 2009/2010: 50, 2010/2011: 30). Of these swans, 48 were equipped with a coded neck collar containing a GPS data logger (2006/2007: 12, 2009/2010: 23, 2010/2011: 13). This logger recorded the GPS location of the swans two (2006/2007), four (2009/2010) or eight (2010/2011) times per day (detailed information in Supplementary material Appendix 1 and 2) for a full year. The swans were aged by plumage colour, biometrics measurements were taken, and a blood sample was drawn for molecular sexing. As part of another experiment, some swans were injected with 1) phytohemagglutinin , 2) a low-pathogenic avian influenza virus, 3) phosphate-buffered saline or 4) not treated (Hoye et al. 2011; Supplementary material Appendix 3). These treatments were anticipated to have short-term effects, but none of these treatments resulted in significant differences in short-term displacements ( $<30 \mathrm{~d}$ post-catch; if anything, treated birds moved further; Hoye et al. 2011), and therefore 
we assume any effects on long-term displacement (i.e. migration) can be safely disregarded.

In the winter after capture the swans were located with the help of volunteer observers who entered their sightings at a ring data entry website. At set times each day, a Bluetooth connection could be established between the collar and an antenna connected to a computer, within $400 \mathrm{~m}$ of the bird, to download the data. The social status (single/paired, with/ without young) and a condition score (abdominal profile index; Bowler 1994) of the bird were visually estimated. In total, 17 complete annual trajectories were collected (2006/2007: 4, 2009/2010: 6, 2010/2011: 7). One of the $2006 / 2007$ birds was a juvenile at the time of ringing, and was excluded from the analysis. A swan of the 2009/2010 catch was a yearling but came back with offspring so was included in the analysis with all adult birds. Furthermore, two of the 2009/2010 birds proved to be a pair, moving together, hence only one of these was included in the analyses (Supplementary material Appendix 1-3). This resulted in a sample size of 15 complete annual tracks.

The trajectories of swans were visualized in Google Earth and distances between geographic coordinates were calculated using the Haversine formula (Great Circle Distance). For each tracked swan, the winter and summer staging areas were determined using the criterion that the bird stayed within an area of $400 \mathrm{~km}$ in diameter for $80 \mathrm{~d}$ or more. The distance criterion was set so that all main wintering areas of the population - British Isles, the Netherlands and NW-Germany (Rees 2006) - would fall within it. The time criterion was based on the staging time in summer because the distance criterion is not limiting here and in the trajectories it was clear when the birds arrived and departed their breeding sites. A stop-over site was designated when a swan did not move more than $30 \mathrm{~km}$ between two consecutive GPS fixes for more than $48 \mathrm{~h}$ (adapted from Van Wijk et al. 2012). The $48 \mathrm{~h}$ criterion originates from the fact that birds need to rest and explore a site before they choose to stay and start to refuel (Hedenström and Alerstam 1997). Sometimes the swans made a detour but returned to the same stop-over site; if this detour took less than $48 \mathrm{~h}$, it was considered to be the same stop-over site; if more than $48 \mathrm{~h}$, a new stop-over site was assigned. We were able to determine arrival and departure at stop-over sites as in spring the collars collected positions on $45.8 \%$ (2007), $95.3 \%$ (2010) and $99.7 \%$ (2011) of the days during migration between site 1 and 5 (day 94 till day 144), and in autumn (day 271 till 300) these numbers were similar (2007: 57.8\%, 2010: 94.0\% and 2011: 100\%).

\section{Migration speed and comparison with ice cover}

Within the northern half of the migration, where ice is always formed during winter, we identified four areas in which consecutive stop-over sites of most individuals were situated and numbered these from 1 in the south to 4 in the north. The wintering area was numbered 0 and the breeding area was numbered 5 (Fig. 1, Supplementary material Appendix 4, Fig. A1-A2). Only at the sites in the northern part of the migratory route, sites 1 to 5 , the swans may have encountered ice cover. In this part they also primarily feed on aquatic vegetation (Nolet et al. 2001, Hoye et al. 2012) such that ice cover potentially constrains them (in winter they mainly feed on land, Van Gils and Tijsen 2007, Van Gils et al. 2008).

Migration consists of both stop-over and flight intervals, and both are included in the calculation of migration speed. In order to test whether we should take into account the stop-over before or after a flight interval, we tested if stopover duration related to flight durations before or after stopover. We used two general linear mixed models fit by maximum likelihood ( $\mathrm{R}$ package lme4). In the first model, flight distance following a stop-over was modelled as a function of the preceding stop-over duration, season (and their interaction) and year, with bird ID as a random factor. In the second model, stop-over duration was modelled as a function of the preceding flight distance, season (and their interaction) and year, again with bird ID as a random factor. For both models, we used Akaike's information criterion to evaluate model fits. It appeared that flight distance was related to the preceding stop-over duration (first model: $\mathrm{t}=3.28, \mathrm{p}<0.002)$, but that stop-over duration was not related to the preceding flight distance (second model: $\mathrm{t}=0.07$, NS) nor its interaction with season $(\mathrm{t}=-1.65$, $\mathrm{p}>0.01)$. So, we included stop-over duration before the flight into the calculation of migration speed, and hence used stop-over arrival times instead of departure times for comparison to ice melt/formation in both seasons. Note that for site 5 in autumn we could not derive stop-over arrival (and thus duration) from the data, because most birds used this as their summer staging area. To exclude breeding time from autumn migration, we took departure time from this site and included the (unknown) fuelling time before departure by adding the average stop-over duration (which gives an indication of fuelling time) of birds $(\mathrm{n}=5)$ that used site 5 as an autumn stop-over only $(18.4 \mathrm{~d} \pm 2.7 \mathrm{SE})$ to the departure date from site 5 of the birds that used site 5 as a summer staging (breeding) area $(n=9)$ or only briefly stopped there $(n=1)$.

The arrival of the swans at each of the five sites in spring and autumn was derived from their trajectories and compared among years. Migration speed per swan $\left(\mathrm{V}_{\text {migr }}\right)$ was calculated as (Alerstam 2003):

$$
\begin{aligned}
\mathrm{V}_{\text {migr }}=\mathrm{D}_{\mathrm{ij}} / \mathrm{T}_{\mathrm{ij}} & ; \text { spring: } \mathrm{i}=1, \mathrm{j}=5 \\
& ; \text { autumn: } \mathrm{i}=5, \mathrm{j}=1
\end{aligned}
$$

where $D_{i j}$ is the distance $(\mathrm{km})$ between sites $\mathrm{i}$ and $\mathrm{j}$ and $\mathrm{T}_{\mathrm{ij}}$ is the time (d) between arrival dates at these two sites. Because of difficulties with finding a good indication for fuelling time before departure on spring migration (from site 0 ), we did not calculate migration speed from site 0 to 5 , but only from site 1 (for which stop-over duration was derived from the trajectories) to 5 (and vice versa for autumn). This is also the more relevant geographical part of the migration for our study, because of regular winter ice in this region.

Ice cover maps were obtained from the Interactive Multisensor Snow and Ice Mapping System (IMS) from the National Snow and Ice Data Centre (NSIDC) in Boulder, USA (National Ice Center 2008). The maps were derived from satellite images and show the ice cover in the northern hemisphere at a $4 \times 4 \mathrm{~km}$ resolution. This is rather course compared with spatial use of the swans, but in the 

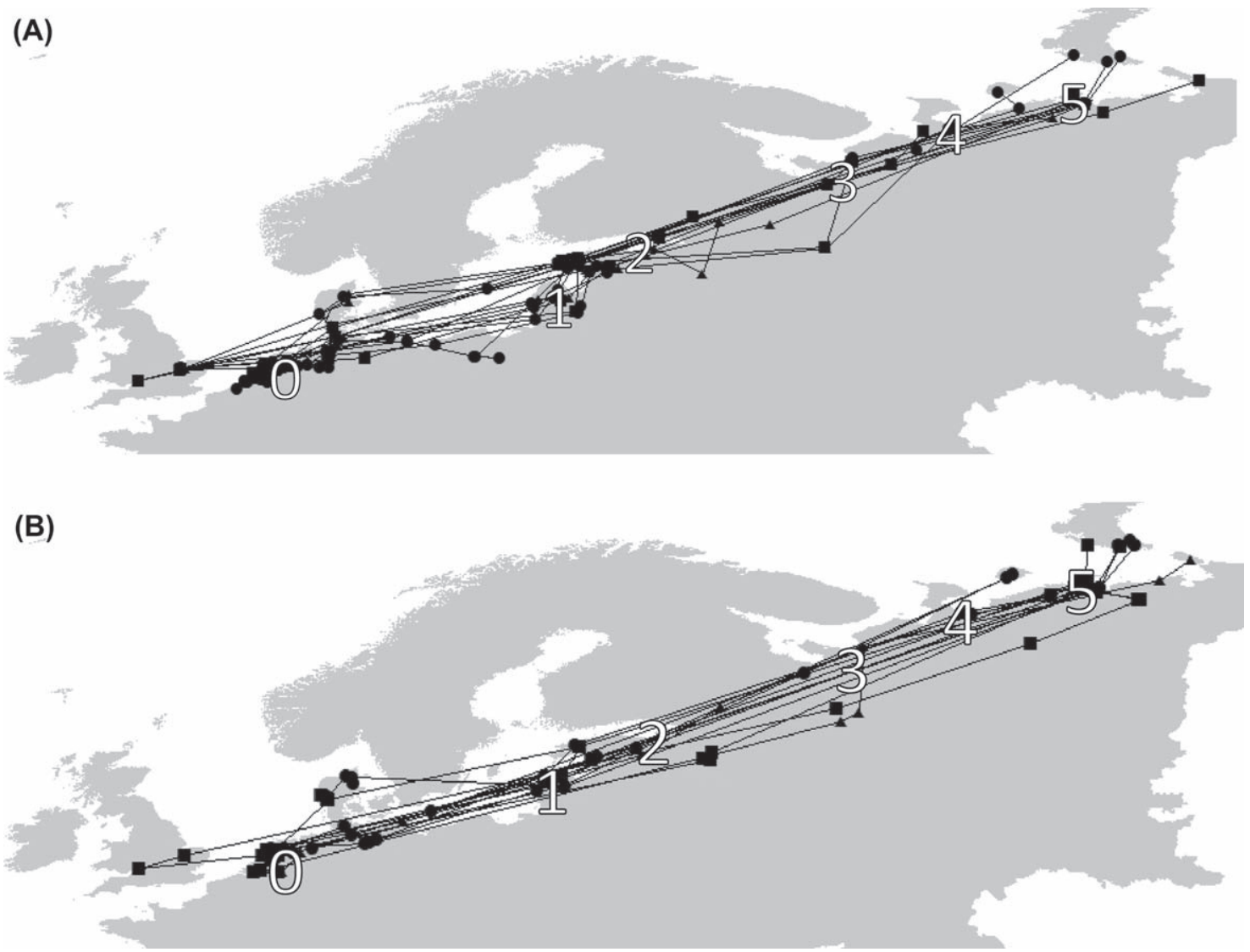

Figure 1. Swan trajectories $(n=15)$ after determination of stop-over sites ( $\geq 48 \mathrm{~h}, \leq 30 \mathrm{~km} ; 2007$ triangles, 2010 squares, 2011 circles) and winter/summer staging areas ( $\geq 80 \mathrm{~d}, \leq 400 \mathrm{~km}$ ) in spring (A) and in autumn (B). White numbers represent the sites where ice cover was quantified (1: Gulf of Riga, 2: Gulf of Finland, 3: Dvina Bay, 4: Cheskaya Bay, 5: Pechora Bay). 0 represents the wintering area.

light of how rapidly ice cover changed (Fig. 2), this resolution is suitable for our study. The ice cover was quantified at the shallow, coastal water areas within the five sites $(20$ fixed pixels along the coast per site) for every day of the three years (2007, 2010 and 2011) using ArcGIS 10.0 (Supplementary material Appendix 4, Fig. A3). From this data the days of 25, 50 and $75 \%$ ice cover in both spring and autumn were derived for each year. In spring the last day with these coverage levels was taken because this day would constrain the swans most, and in autumn the first day with these coverage levels was taken for the same reason. Ice speed $\left(\mathrm{V}_{\text {ice }}\right)$ was calculated with the following formula:

$$
\begin{aligned}
\mathrm{V}_{\text {ice }}=\mathrm{D}_{\mathrm{ij}} / \mathrm{T}_{\mathrm{ij}} \text { 50\%ice } & \text {; spring: } \mathrm{i}=1, \mathrm{j}=5 \\
& \text {; autumn: } \mathrm{i}=5, \mathrm{j}=1
\end{aligned}
$$

where $\mathrm{D}_{\mathrm{ij}}$ is the great circle distance $(\mathrm{km})$ between two geographic locations, and $\mathrm{T}_{\mathrm{ij}} 50 \%$ ice is the time (d) between the days of $50 \%$ ice cover at these sites.

\section{Statistical analysis}

For the observations of captive swans, the time spent preening was square-root transformed to obtain normality. Subsequently, the time each individual spent preening was averaged per week. In an over-parameterized, general linear model (procedure glm; StatSoft), time spent preening was tested against the categorical variables period, pair, bird ID (random factor, nested in random factor pair), and collar (yes/no), and continuous predictor week, with the interaction collar $\times$ week. For graphical purposes, a modified ratio, Ivlev's index, $\left(\mathrm{p}_{\mathrm{c}}-\mathrm{p}_{\mathrm{n}}\right) /\left(\mathrm{p}_{\mathrm{c}}+\mathrm{p}_{\mathrm{n}}\right)$, was calculated, where $\mathrm{p}_{\mathrm{c}}$ and $\mathrm{p}_{\mathrm{n}}$ are the duration of preening of the collared bird and control bird of a pair, respectively. This expresses whether, within a pair, a collared bird preened more or less than the control bird. For the possible effect of the collar on a change in weight $(\mathrm{dW})$, the same general linear model was used.

Comparability of GPS data from the free-ranging swans between years, despite the difference in fix frequency, was assessed by comparing the (total) distances recorded by the collars within a set time-frame (8 January to 9 November) using a one-way ANOVA. The total distances tracked by the collars were similar $\left(\mathrm{F}_{2,12}=2.3, \mathrm{p}=0.139\right)$ across the three years, even more so after the movements within stopover sites were excluded from the analyses $\left(\mathrm{F}_{2,12}=0.8\right.$, $\mathrm{p}>0.4)$. Hence for the migration-speed analyses movements within stop-over sites were disregarded (Supplementary material Appendix 5, Fig. A4).

Stop-over frequencies and durations per season were analysed with a general linear model using year and season as fixed factors and bird ID as a random factor. Migration speed 


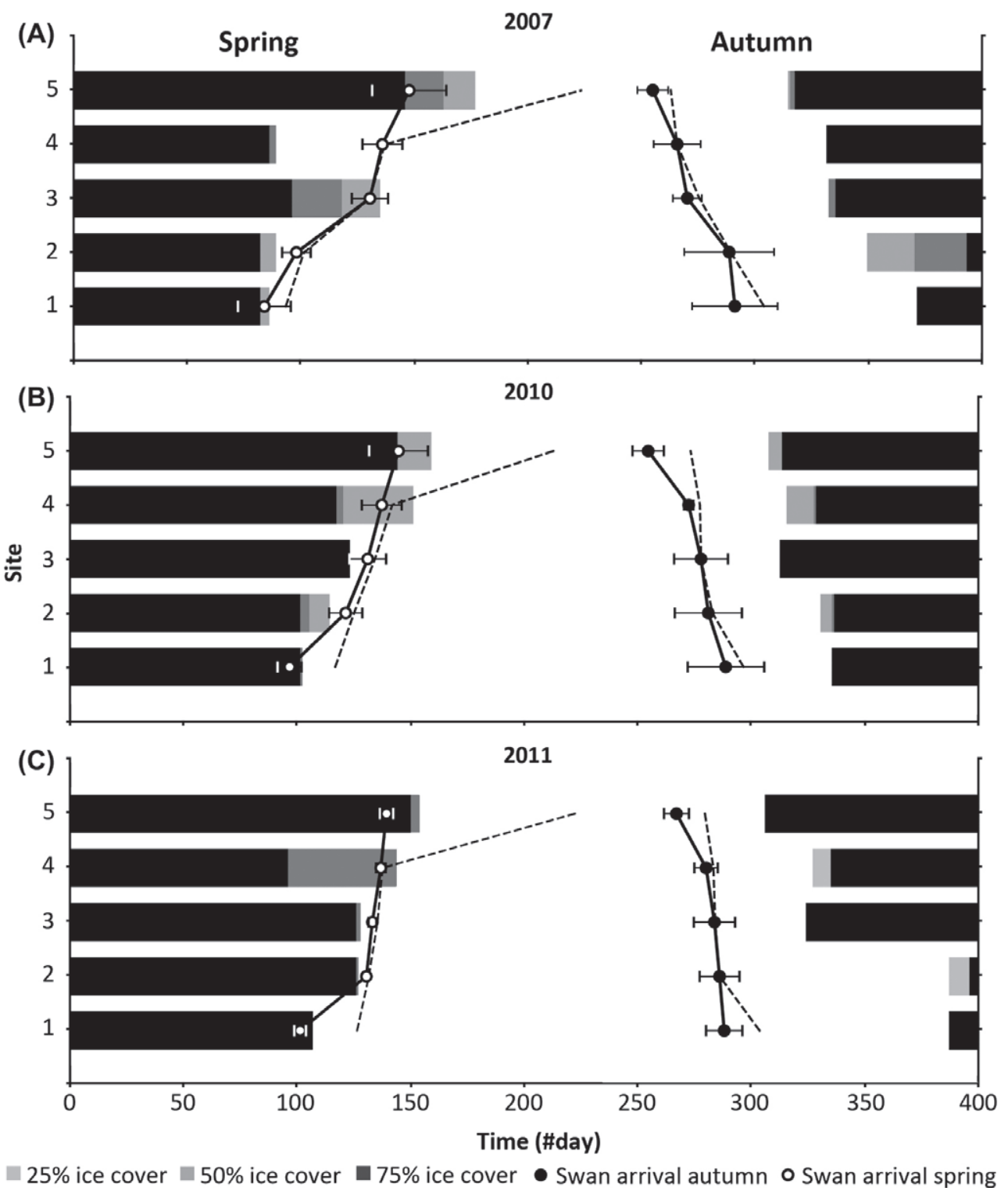

Figure 2. Timing in days (cumulative number of days, starts at 1 January of particular year) of ice cover (bars), swan arrival (solid line) and departure (dotted line) at the five sites in $2007(\mathrm{~A}, \mathrm{n}=3), 2010(\mathrm{~B}, \mathrm{n}=5)$ and $2011(\mathrm{C}, \mathrm{n}=7)$ for spring (left) and autumn (right). In spring the swans arrive when the ice is melting, in autumn they arrive and depart well in advance of ice formation. Error bars indicate $95 \%$ confidence intervals. For site names see Fig. 1.

(site 1-5) was analysed using a linear mixed model with year and season as fixed factors and individual as a random factor, using maximum likelihood estimation (procedure lmer in package lme4, $\mathrm{R}$ ver. 2.15.3). The interaction between year and season did not improve the model $\left(\chi_{2}^{2}=0.0032, \mathrm{p}>0.99\right)$, and was omitted from further analysis. We used an ANOVA with Tukey post hoc comparison to test, for both seasons, for differences in migration speed among years.

Within each year and for each season, migration speed between sites 1 and 5 was compared with ice speed of that same period using a one-sample t-test (with Bonferroni corrected alpha $=0.017$ ). The arrival of the swans at the different sites was compared among years with a one-way ANOVA with Bonferroni post hoc test for both spring and autumn.

\section{Results}

\section{Testing of GPS collars}

The captive birds generally preened more in period 1 (June-July) than in period 2 (September-October) $\left(\mathrm{F}_{1,112}=\right.$ 95.3, $\mathrm{p}<0.0001)$, and collared birds preened more than control birds $\left(\mathrm{F}_{1,112}=14.4, \mathrm{p}<0.0003\right)$. The interaction collar $\times$ week was significant $\left(\mathrm{F}_{1,112}=5.6, \mathrm{p}<0.02\right)$, indicating that the difference between the collared birds and their control mates changed over time. Ivlev's index also showed this pattern, with significantly more preening by GPS collared birds than their control in week 2 of period 1, and week 3 and 4 of period 2 (Fig. 3). Splitting the periods in two equal halves (and excluding week and the interaction collar $\times$ week) yielded a significant difference 


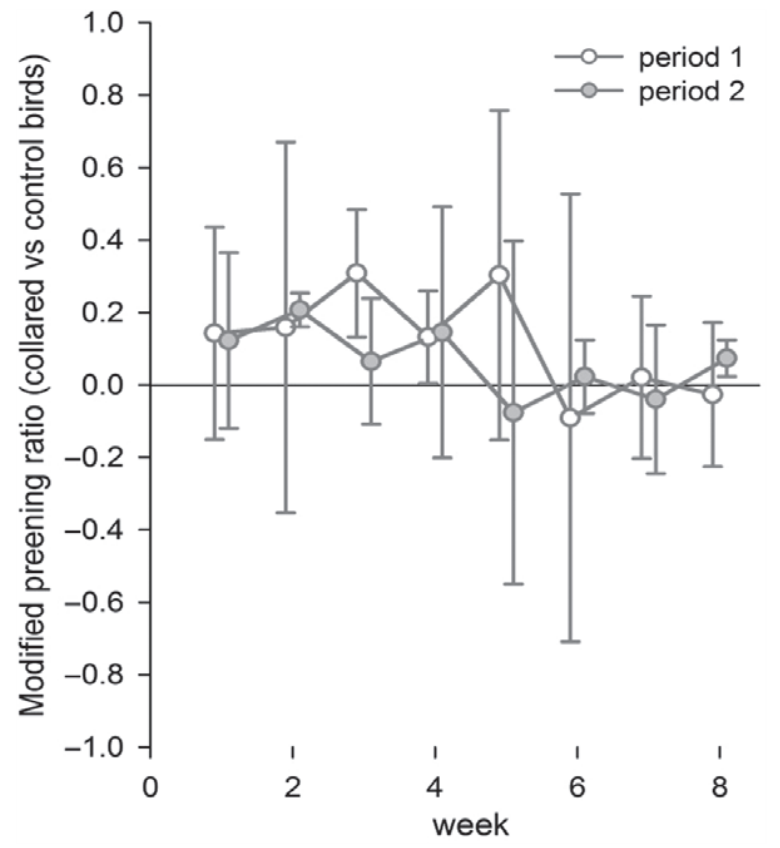

Figure 3. Average modified ratio of preening duration of GPS collared birds versus control pair mate in captivity, measured in two periods (June-July and September-October). Positive values indicate more preening by the collared bird, while negative values reflect more preening by the control bird. Error bars indicate $95 \%$ confidence intervals. Collared birds tend to preen more in the first four weeks after collaring, but not thereafter.

between collared and control birds in the first four weeks $\left(\mathrm{F}_{1,54}=16.4, \mathrm{p}<0.0002\right)$, but this difference disappeared in the second four weeks $\left(\mathrm{F}_{1,50}=0.16, \mathrm{p}>0.6\right)$.

The collar did not have a significant effect on the weight of the swans, nor did the interaction collar $\times$ week. Period did have a significant effect $\left(\mathrm{F}_{1,112}=5.0, \mathrm{p}<0.03\right)$, where the weight of the swans almost stayed constant in the first period ( $\left.\mathrm{dW}=1 \pm 6 \mathrm{~g} \mathrm{~d}^{-1}\right)$, while in the second period they gained weight $\left(\mathrm{dW}=15 \pm 11 \mathrm{~g} \mathrm{~d}^{-1}\right)$, irrespective of wearing a collar or not.

\section{Swan trajectories and ice cover during migration}

At the five examined sites, the timing of ice cover changes differed only slightly among the three years (Fig. 2). The arrival of swans was significantly different among years at site $1\left(\mathrm{~F}_{2,12}=7.9, \mathrm{p}=0.006,\right)$ and site $2\left(\mathrm{~F}_{2,12}=48.3\right.$, $\mathrm{p}<0.001)$ during spring migration, and at site $4\left(\mathrm{~F}_{2,12}=9.2\right.$, $\mathrm{p}=0.004)$ and site $5\left(\mathrm{~F}_{2,12}=5.9, \mathrm{p}=0.016\right)$ during autumn migration. In spring, ice retreat and the arrival of swans was close at all five sites $(0.7 \pm 4.1 \mathrm{~d}$, average $\pm \mathrm{SE})$, in all three years. In contrast, in autumn ice cover formed long after the swans had arrived (and departed) at a particular site in all three years (75.9 $\pm 16.1 \mathrm{~d}$; Fig. 2).

In spring, individual swans stopped on average $5.0 \pm 0.3$ (average \pm SE) times during total migration (site $0-5$ ) while in autumn this was only $1.8 \pm 0.3$ times. Between sites $1-5$, and vice versa, this was $2.9 \pm 0.3$ for spring and $1.3 \pm 0.3$ for autumn. All swans stopped significantly more in spring than in autumn (sites 0-5: $\mathrm{F}_{1,12}=484.8, \mathrm{p}<0.001$; sites 1-5:
$\left.\mathrm{F}_{1,12}=138.1, \mathrm{p}<0.001\right)$. On average, the total (cumulative) duration of all stop-overs between sites 1 and 5 was 34.4 $\mathrm{d} \pm 2.8$ (average, $\pm \mathrm{SE}$ ) in spring and $11.2 \mathrm{~d} \pm 2.8$ in autumn. The average stop-over duration for each stopover was $12.8 \mathrm{~d} \pm 1.3 \mathrm{in}$ spring and $7.0 \mathrm{~d} \pm 1.7$ in autumn. Both the total stop-over duration $\left(\mathrm{F}_{1,12}=96.4, \mathrm{p}<0.001\right)$ and the average duration per site $\left(\mathrm{F}_{1,12}=101.3, \mathrm{p}<0.001\right)$ was significantly higher in spring than in autumn.

Migration speed was significantly lower in spring $\left(40.7 \pm 2.4 \mathrm{~km} \mathrm{~d}^{-1}\right.$, average $\left.\pm \mathrm{SE}\right)$ than in autumn $\left(60.5 \pm 4.8 \mathrm{~km} \mathrm{~d}^{-1} ; \chi^{2}=15.4, \mathrm{p}<0.001\right)$. When both spring and autumn were combined, these migration speeds did not differ among years $\left(\chi_{2}^{2}=5.4, p=0.07\right.$; Fig. 4). Analysing the seasons separately, migration speeds did not differ among years in autumn $\left(\mathrm{F}_{2,12}=1.0, \mathrm{p}=0.407\right)$, but they did differ in spring $\left(\mathrm{F}_{2,12}=7.9, \mathrm{p}=0.007\right)$, with 2007 and 2011 being significantly different from one another $(t=3.96, p<0.005$; Fig. 4). In 2007 and 2010, migration speed did not differ from ice speed in both seasons (2007, spring: $\mathrm{p}=0.255$, autumn: $\mathrm{p}=0.046 ; 2010$, spring: $p=0.459$, autumn: $p=0.386$ ), but in 2011 swan migration proceeded faster than ice cover changed in both seasons (spring: $\mathrm{p}=0.014$, autumn: $\mathrm{p}=0.002$ ) (Fig. 4).

\section{Discussion}

Avian migration is generally considered to proceed faster in spring than in autumn, both for ultimate and proximate reasons. Here, however, we demonstrate that in Bewick's swans, spring migration is environmentally constrained by the retreating ice whilst this is not the case in autumn. As a result, spring migration speed corresponds with the speed the ice front is retreating, and is approximately only half the speed of the swans' autumn migration.

In spring, the arrival of the swans closely corresponds with the disappearance of ice cover (Fig. 2), which, together with a higher speed in autumn, is in accordance with the second hypothesis posed by Petrie and Wilcox (2003) that migrating swans are delayed by ice cover in spring. This is substantiated by the result that in two of the three years, spring migration speeds (from sites 1-5) did not differ from the corresponding ice speeds. In the other year (2011), spring migration was faster than the retreating ice. In 2011, the ice retreated a few days later than in the other two years at four out of the five sites. Accordingly (by following the retreating ice), the swans arrived later at site 1 and 2 in 2011 than in other years (Fig. 2). Interestingly, this difference in arrival times disappeared from site 3 onwards.

Our data suggest that ice cover determined the speed of swan migration in spring up to a certain point, after which factors other than food availability start playing a role. In the first (site 0 to 1 ) and middle (site 1 to 3 ) part of spring migration, refuelling and accumulating resources for reproduction appears to be important for the swans. To be able to fuel, the swans must wait for the ice to melt because they feed on aquatic vegetation throughout migration (Nolet et al. 2001). In the last part of spring migration (site 3 to 5) however, the swans are potentially more constrained by the approaching summer, and time becomes more important. In order to complete the whole breeding cycle successfully 


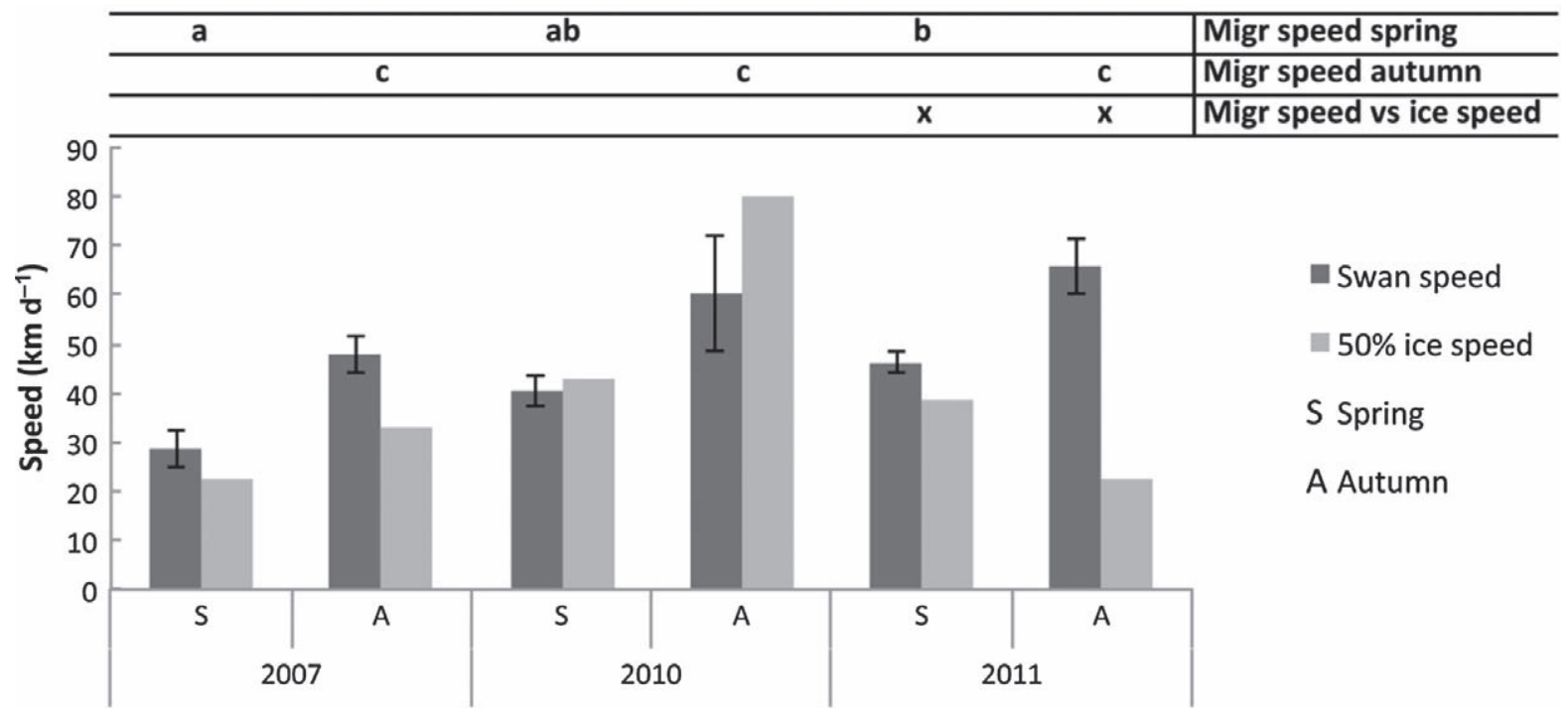

Figure 4. Average swan migration speed $\left(\mathrm{km} \mathrm{d}^{-1}\right)$ in spring and in autumn in 2007, 2010 and 2011 together with ice speed of the same year and season. Significant differences are indicated above the bars. In spring swan speeds differed significantly among the years, with 2007 (a) being slower than 2011 (b). In autumn the swan speeds did not differ among years (c). Both in spring and autumn the swan speeds differed from the ice speeds only in 2011. Error bars indicate the standard error of the mean for the swan speeds.

(from acquiring a breeding territory to fledging of cygnets roughly takes $110 \mathrm{~d}$, Beekman et al. 2002), swans must arrive at the breeding grounds on time (Mathiasson 1991). In 2011, the swans we tracked accelerated in the last part of their spring migration (Fig. 2), potentially to keep pace with the advancing season. Being closer to the breeding grounds, the birds might also be better capable of predicting the circumstances there (Tombre et al. 2008). This 'time-stress' experienced by the swans in the last part of spring migration is further supported by the fact that the swans arrived on the breeding grounds on roughly the same day in all three years (day 145 $\pm 3.8,25$ May, Fig. 2), and by the slightly higher average migration speed of the swans in spring 2011 (Fig. 4). This 'time-stress' in the latter part of spring migration, in relation to an optimal arrival date at the breeding grounds, was also noted in a comparison of individual-based model output and data of migrating pinkfooted geese Anser brachyrhynchus, where a shift from external departure cues in the first part of spring migration to time-related cues in the last part of spring migration was found (Duriez et al. 2009). This strategy may sound familiar to what Alerstam (2006) expects in birds competing for arrival at the breeding grounds (a 'final sprint'), but the swans are still reliant on the stores they gathered on the way for breeding (captital breeding strategy).

In autumn, the advance of ice cover was, on average, more than a month behind the swans' arrival in all three years (Fig. 2). Given the time-stress in spring, it is surprising that the swans leave the breeding grounds so much earlier than ice formation. The swans stopped only a few times in autumn, and even then only briefly (on average $7.0 \mathrm{~d} \pm 1.7$ per stop-over), so stop-over duration does not explain the large gap between swan arrival and ice formation (Fig. 2). It has previously been noted that there are two waves of migration; one with non-breeders or nonsuccessful breeders and one with successful breeders that possibly have to wait for their offspring (Evans 1980, Luigujóe et al. 1996, Rees and Bacon 1996). It is known that successful breeders sometimes also feed on tundra vegetation in autumn (particularly berries; Rees et al. 1997, Ubels et al. 2000), so for these birds this could explain the gap between departure and ice cover (as snow cover will already constrain grazing on land). However, most birds in this study did not breed successfully (Supplementary material Appendix 3) and will have been feeding on aquatic vegetation (Hoye et al. 2012). By analysing temperature data of Nar'jan Mar $\left(67^{\circ} 38^{\prime} \mathrm{N}, 53^{\circ} 02^{\prime} \mathrm{E}\right)$ (NOAA NCDC 2013) we found that there is considerable annual variability in the onset of winter. Averaged over all years with available data $(\mathrm{n}=83)$, winter started (measured as the first day the maximum temperature, Tmax, fell below zero) at day 286 of the year (13 October) with a standard deviation of 7.4. This variability is not enough to explain the gap between the swans' departure and the $50 \%$ ice coverage. However, the swans' departure date $(271 \pm 8.8$, average \pm SD) was close to the very first day Tmax was below zero in this series of years (day 269). The lower critical temperature of swans is above $0^{\circ} \mathrm{C}$ (Bech 1980, Nespolo et al. 2008, M. Klaassen and B. van Lith unpubl.). We therefore suggest that the swans might leave in autumn before temperature becomes sub-zero. In fact, we cannot exclude the possibility that the reverse holds true for spring.

Recently, much emphasis has been placed on climate change and its effects on migratory birds (Knudsen et al. 2011). One might argue that present-day behaviour of the swans is tuned to past conditions, and that the early departure in autumn relative to ice formation may be a reflection of earlier ice formation in the past. However, within the temperature data from Nar'jan Mar, we found no trend in sub-zero temperature shifting either forwards or backwards in time over nearly a century $\left(\mathrm{R}^{2}=0.023 ; \mathrm{n}=83\right.$, $\mathrm{p}=0.167)$. So, as far as we can say, there is no such effect for 
the Bewick's swan concerning ice formation when departing on autumn migration.

Finally, there is one other hypothesis that could potentially explain the slower spring migration in swans. For most birds, conditions during spring migration are purportedly better due to, amongst others, higher food abundance in spring than in autumn (Van der Graaf et al. 2006). Swans, however, feed on tubers of aquatic vegetation during migration (Nolet et al. 2001, Hoye et al. 2012). Aquatic vegetation only grows in summer and tubers are formed then. Due to depletion by foraging swans in autumn and winter mortality of tubers, food abundance might actually be lower in spring than in autumn. However, the swans only visit stop-over sites briefly in autumn (Beekman et al. 2002, this study), causing little depletion, and visit different sub-sites within larger stop-over sites in spring and autumn (Luigujóe et al. 1996). Data from previous studies show that there is little difference between average food density in spring and autumn (spring: 26.7-27.6 g $\mathrm{m}^{-2}$; autumn: 12.9-32.6 $\mathrm{g} \mathrm{m}^{-2}$; Hidding et al. 2009, 2010, Klaassen et al. 2010). Therefore, it seems unlikely that differences in food abundance cause the difference in migration speed found in Bewick's swans between spring and autumn.

In the captive trials, the swans appeared to become accustomed to the GPS collars within about four weeks. This implies that the free-living birds equipped with collars in the field had ample time to become accustomed to their collar before spring migration commenced. We do not know how the collar affected their flight performance, but in order to ensure comparability of the different trajectories, only adult swans were included. The use of GPS devices in tracking animal movements is currently under rapid development (Robinson et al. 2009). Higher resolution of trajectories in later years has to be taken into account in order to ensure data comparability. Here, omitting the movements within stop-over sites made the data comparable among years and gave a better representation of the actual migration distance and speed.

With this study we have gained more insight in the constraints that shape the migration of Bewick's swans. It is plausible that other northerly migrating birds that feed on aquatic resources encounter similar restrictions on migration speed, and the phenomenon of a slower migration in spring than in autumn may not be an exception in this guild of birds. It would be interesting to see whether years that the birds encounter a delay in the middle part of their spring migration, like 2011, will eventually show reductions in survival or reproduction in comparison with years without such a delay. If the time constraint on spring migration becomes less severe under expected climatic warming, the swans might be able to adjust their migration (Marra et al. 2005) in order to lessen their time-stress during spring migration and breeding and thereby increase their reproductive output. Understanding this phenomenon is important to understand future population dynamics of this large migratory bird.

Acknowledgements - We would like to thank Willemijn Beulink, Thijs de Boer, Symen Deuzeman, Cynthia Lange, Coco Teheux, Wim Tijsen and many volunteers for assistance during catching of the swans and downloading of the logger data. We thank Bart van Lith for his part of the observations of the captive swans. Merel Soons kindly measured the fixed positions with her DGPS. We thank Theo Gerrits for providing us with 20 replacement loggers and his technical support, and Sven Teurlincx for his support with the ArcGIS analysis. Special thanks go to all observers who entered their swan observations at the website or guided us to the logger swans by other means. We thank Raymond Klaassen for constructive comments to a draft of this manuscript. The experiments were approved by the KNAW Animal Welfare Committee (DEC protocols CL06.06, CL08,05, NIOO10.08, and NIOO10.11), and, insofar it concerned wild-caught swans, licenced by exemptions Flora- en Faunawet $75 \mathrm{~A}$ obtained through Dienst Regelingen. The study was financially supported by the Royal Netherlands Academic of Arts and Sciences (KNAW Vernieuwingsfonds and KNAW Strategiefonds), the Netherlands Organisation for Scientific Research (NWO grant 851.40.073 to $\mathrm{MK}$ ), and the Schure-Beijerinck-Popping Fund. This is publication 5507 of the Netherlands Inst. of Ecology.

\section{References}

Alerstam, T. 2003. Bird migration speed. - In: Avian migration. Springer, pp. 253-267.

Alerstam, T. 2006. Strategies for the transition to breeding in timeselected bird migration. - Ardea 94: 347-357.

Alerstam, T. 2011. Optimal bird migration revisited. - J. Ornithol. 152: 5-23.

Alerstam, T., Hedenström, A. and Åkesson, S. 2003. Longdistance migration: evolution and determinants. - Oikos 103: $247-260$

Alerstam, T., Hake, M. and Kjellén, N. 2006. Temporal and spatial patterns of repeated migratory journeys by ospreys. - Anim. Behav. 71: 555-566.

Bauchinger, U. and Klaassen, M. 2005. Longer days in spring than in autumn accelerate migration speed of passerine bird. - J. Avian Biol. 36: 3-5.

Bech, C. 1980. Body temperature, metabolic rate, and insulation in winter and summer acclimatized mute swans (Cygnus olor). - J. Compar. Physiol. 136: 61-66.

Beekman, J. H., Van Eerden, M. R. and Dirksen, S. 1991. Bewick's swans Cygnus columbianus bewickii utilising the changing resource of Potamogeton pectinatus during autumn in the Netherlands. - Wildfowl Suppl. 1: 238-248.

Beekman, J. H., Nolet, B. A. and Klaassen, M. 2002. Skipping swans: differential use of migratory stop-over sites in spring and autumn in relation to fuelling rates. - Ardea 90: 437-460.

Berthold, P. 1996. Control of bird migration. - Chapman and Hall.

Bowler, J. M. 1994. The condition of bewick's swans Cygnus columbianus bewickii in winter as assessed by their abdominal profiles. - Ardea 82: 241-241.

Drent, R. H. and Daan, S. 1980. The prudent parent: energetic adjustments in avian breeding. - Ardea 68: 225-252.

Duriez, O., Bauer, S., Destin, A., Madsen, J., Nolet, B. A., Stillman, R. A. and Klaassen, M. 2009. What decision rules might pink-footed geese use to depart on migration? An individual-based model. - Behav. Ecol. 20: 560-569.

Evans, M. E. 1980. The effects of experience and breeding status on the use of a wintering site by Bewick's swans Cygnus columbianus bewickii. - Ibis 122: 287-297.

Evans, M. E. 1982. Movements of Bewick's swans, Cygnus columbianus bewickii marked at Slimbridge, England from 1960 to 1979 . - Ardea 70: 59-75.

Fransson, T. 1995. Timing and speed of migration in north and west European populations of Sylvia warblers. - J. Avian Biol. 26: $39-48$. 
Hedenström, A. and Alerstam, T. 1995. Optimal flight speed of birds. - Phil. Trans. R. Soc. B 348: 471-487.

Hedenström, A. and Alerstam, T. 1997. Optimum fuel loads in migratory birds: distinguishing between time and energy minimization. - J. Theor. Biol. 189: 227-234.

Hedenström, A. and Alerstam, T. 1998. How fast can birds migrate? - J. Avian Biol. 29:424-432.

Hidding, B., Nolet, B. A., van Eerden, M. R., Guillemain, M. and Klaassen, M. 2009. Burial depth distribution of fennel pondweed tubers (Potamogeton pectinatus) in relation to foraging by Bewick's swans. - Aquat. Bot. 90: 321-327.

Hidding, B., Bakker, E. S., Keuper, F., de Boer, T., de Vries, P. P. and Nolet, B. A. 2010. Differences in tolerance of pondweeds and charophytes to vertebrate herbivores in a shallow Baltic estuary. - Aquat. Bot. 93: 123-128.

Hoye, B. J., Munster, V. J., van Dijk, J., Duden, A., Huig, N., Kuiken, T., Lexmond, P., Nolet, B. A., Oosterbeek, K., Tijsen, W., Verhagen, J., Vos, A., de Vries, P., Wietses, W., Klaassen, M. and Fouchier, R. A. M. 2011. Consequences of low pathogenic avian influenza virus infection in free-living migrants. An experimental assessment. - In: Hoye, B. J. (ed.), Host-pathogen interactions on the move. PhD thesis, Utrecht Univ., Utrecht, pp. 169-191.

Hoye, B. J., Hahn, S., Nolet, B. A. and Klaassen, M. 2012. Habitat use throughout migration: linking individual consistency, prior breeding success and future breeding potential. - J. Anim. Ecol. 81: 657-666.

Karlsson, H., Nilsson, C., Bäckman, J. and Alerstam, T. 2011. Nocturnal passerine migrants fly faster in spring than in autumn: a test of the time minimization hypothesis. - Anim. Behav. 83: 87-93.

Kemp, M. U., Shamoun-Baranes, J., van Gasteren, H., Bouten, W. and van Loon, E. E. 2010. Can wind explain seasonal differences in avian migration speed? - J. Avian Biol. 41: 672-677.

Klaassen, M. 2003. Relationships between migration and breeding strategies in arctic breeding birds. - In: Berthold, P., Gwinner, E. and Sonnenschein, E. (eds), Avian migration. Springer, pp. 237-249.

Klaassen, M., Hangelbroek, H. H., de Boer, T. and Nolet, B. A. 2010. Insights from the eco-physiological book of records: Bewick's swans outperform the canonical intake-maximizing vertebrate. - Oikos 119: 1156-1160.

Klaassen, R. H. G., Ens, B. J., Shamoun-Baranes, J., Exo, K. M. and Bairlein, F. 2012. Migration strategy of a flight generalist, the lesser black-backed gull Larus fuscus. - Behav. Ecol. 23: 58-68.

Knudsen, E., Lindén, A., Both, C., Jonzén, N., Pulido, F., Saino, N., Sutherland, W. J., Bach, L. A., Coppack, T. and Ergon, T. 2011. Challenging claims in the study of migratory birds and climate change. - Biol. Rev. 86: 928-946.

Kokko, H. 1999. Competition for early arrival in migratory birds. - J. Anim. Ecol. 68: 940-950.

La Sorte, F. A., Fink, D. and Hochachka, W. 2013. Populationlevel scaling of avian migration speed with body size and migration distance for powered fliers. - Ecology 94: 1839-1847.

Lindström, A. 2003. Fuel deposition rates in migrating birds: causes, constraints and consequences. - In: Berthold, P., Gwinner, E. and Sonnenschein, E. (eds), Avian migration. Springer, pp. 307-320.

Luigujóe, L., Kuresoo, A., Keskpaik, J., Ader, A. and Leito, A. 1996. Migration and staging of the Bewick's swan (Cygnus columbianus) in Estonia. - In: Birkan, M., van Vessem, J., Havet, P., Madsen, J., Trolliet, B. and Moser, M. (eds), Proceedings Anatidae 2000 Conference, Strasbourg, France, December 1994. Gibier Faune Sauvage, Game Wildlife, 13: 451-461.
Marra, P. P., Francis, C. M., Mulvihill, R. S. and Moore, F. R. 2005. The influence of climate on the timing and rate of spring bird migration. - Oecologia 142: 307-315.

Mathiasson, S. 1991. Eurasian whooper swan Cygnus cygnus migration, with particular reference to birds wintering in southern Sweden. - Wildfowl Suppl. 1: 201-208.

National Ice Center 2008. IMS daily Northern Hemisphere snow and ice analysis at $4 \mathrm{~km}$ and $24 \mathrm{~km}$ resolution. - National Snow and Ice Data Center, Boulder, CO. Digital media.

Nespolo, R. F., Artacho, P., Verdugo, C. and Castańeda, L. E. 2008. Short-term thermoregulatory adjustments in a South American anseriform, the black-necked swan (Cygnus melanocoryphus). - Compar. Biochem. Physiol. A 150: 366-368.

Newton, I. 2008. The migration ecology of birds. - Academic Press.

Nilsson, C., Klaassen, R. H. G. and Alerstam, T. 2013. Differences in speed and duration of bird migration between spring and autumn. - Am. Nat. 181: 837-845.

NOAA National Climatic Data Centre 2013. - < www.ncdc.noaa. gov $>$.

Nolet, B. A. 2006. Speed of spring migration of tundra swans Cygnus columbianus in accordance with income or capital breeding strategy? - Ardea 94: 579-591.

Nolet, B. A. and Drent, R. H. 1998. Bewick's swans refuelling on pondweed tubers in the Dvina Bay (White Sea) during their spring migration: first come, first served. - J. Avian Biol. 29: $574-581$.

Nolet, B. A., Andreev, V. A., Clausen, P., Poot, M. J. M. and Wessel, E. G. J. 2001. Significance of the White Sea as a stop-over for bewick's swans Cygnus columbianus bewickii in spring. - Ibis 143: 63-71.

Petrie, S. A. and Wilcox, K. L. 2003. Migration chronology of eastern-population tundra swans. - Can. J. Zool. 81: 861-870.

Rees, E. 2006. Bewick's swan. - T and A D Poyser.

Rees, E. C. and Bacon, P. J. 1996. Migratory tradition in Bewick's swans Cygnus columbianus bewickii. - In: Birkan, M., van Vessem, J., Havet, P., Madsen, J., Trolliet, B. and Moser, M. (eds), Proceedings Anatidae 2000 Conference, Strasbourg, France, December 1994. Gibier Faune Sauvage, Game Wildlife 13: 407-420.

Rees, E. C., Bowler, J. M. and Beekman, J. H. 1997. Cygnus columbianus Bewick's swan and whistling swan. - In: Ogilvie, M. A. (ed.), Birds of the Western Palearctic Update. Oxford Univ. Press, pp. 63-74.

Robinson, W. D., Bowlin, M. S., Bisson, I., Shamoun-Baranes, J., Thorup, K., Diehl, R. H., Kunz, T. H., Mabey, S. and Winkler, D. W. 2009. Integrating concepts and technologies to advance the study of bird migration. - Front. Ecol. Environ. 8: 354-361.

Rohwer, S., Ricklefst, R. E., Rohwer, V. G. and Copple, M. M. 2009. Allometry of the duration of flight feather molt in birds. - PLoS Biol. 7: e1000132.

Smith, R. J. and Moore, F. R. 2005. Arrival timing and seasonal reproductive performance in a long-distance migratory landbird. - Behav. Ecol. Sociobiol. 57: 231-239.

Tombre, I. M., Høgda, K. A., Madsen, J., Griffin, L. R., Kuijken, E., Shimmings, P., Rees, E. and Verscheure, C. 2008. The onset of spring and timing of migration in two arctic nesting goose populations: the pink-footed goose Anser brachyrhynchus and the barnacle goose Branta leucopsis. - J. Avian Biol. 39: 691-703.

Ubels, R., Vulink, J. T. and van Eerden, M. R. 2000. Diet of vertebrate herbivores. - In: van Eerden, M. R. (ed.), Pechora Delta: structure and dynamics of the Pechora Delta ecosystems (1995-1999). RIZA report nr: 2000.037 and MD report nr. MD GAE 2000.39. Inst. for Inland Water Management 
and Waste Water Treatment/RIZA, Lelystad, the Netherlands, pp. 223-241.

van der Graaf, A. J., Stahl, J., Klimkowska, A., Bakker, J. P. and Drent, R. H. 2006. Surfing on a green wave - how plant growth drives spring migration in barnacle goose Branta leucopsis. - Ardea 94: 567-577.

van Gils, J. A. and Tijsen, W. 2007. Short-term foraging cost and long-term fuelling rate in central-placed foraging swans revealed by giving-up exploitation times. - Am. Nat. 169: 609-620.

van Gils, J. A., Beekman, J. H., Coehoorn, P., Corporaal, E., Dekkers, T., Klaassen, M., van Kraaij, R., de Leeuw, R. and de Vries, P. P. 2008. Longer guts and higher food quality increase energy intake in migratory swans. - J. Anim. Ecol. 77: 1234-1241.

van Wijk, R. E., Kölzsch, A., Kruckenberg, H., Ebbinge, B. S., Müskens, G. J. D. M. and Nolet, B. A. 2012. Individually tracked geese follow peaks of temperature acceleration during spring migration. - Oikos 121: 655-664.

Yohannes, E., Biebach, H., Nikolaus, G. and Pearson, D. J. 2009. Migration speeds among eleven species of long-distance migrating passerines across Europe, the desert and eastern Africa. - J. Avian Biol. 40: 126-134. 